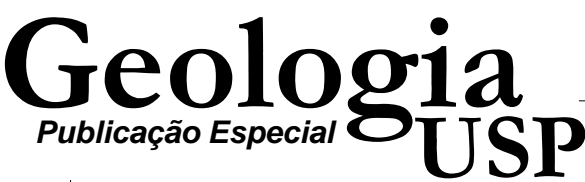

\section{O Atual Currículo do Curso de Geologia - USP e a Demanda de Profissionais Geólogos para a Atuação em Projetos de Áreas Contaminadas}

\author{
Reginaldo Bertolo (bertolo@igc.usp.br) \\ Departamento de Geologia Sedimentar e Ambiental - Instituto de Geociências - USP \\ R. do Lago 562, CEP 05508-080, São Paulo, SP, BRA
}

Recebido em 12 de dezembro de 2006; aceito em 22 de janeiro de 2007

Palavras-chave: educação em Geociências.

\section{RESUMO}

Este trabalho apresenta uma contribuição à discussão da reforma curricular do curso de Geologia-USP considerando a atuação do geólogo em projetos de investigação e remediação de áreas contaminadas. Esta área de atuação vem experimentando forte expansão, principalmente após o surgimento da Lei Federal 9605 de Crimes Ambientais e de sua regulamentação em 1999. Apesar dos esforços na condução dos projetos de remediação dos casos existentes, sabe-se que a maior parte dos problemas ambientais ainda não é conhecida, fazendo acreditar que haverá uma tendência de crescimento da demanda de profissionais para atuar nesta área em longo prazo. Considerando que o geólogo desempenha papel imprescindível e de destaque em projetos de investigação e remediação, principalmente nas etapas de caracterização da geologia, hidrogeologia e da contaminação, acredita-se que algumas disciplinas deverão passar por ajustes para se adequar a algumas das atividades profissionais mencionadas na Resolução CONFEA 1010. Além disso, julga-se necessário realizar uma reavaliação da duração, conteúdo e ordenação temporal de algumas disciplinas geológicas fundamentais, cujos benefícios se estenderiam não somente para a atuação do geólogo em projetos de áreas contaminadas, mas também às demais áreas da Geologia Aplicada.

Keywords: Geosciences education.

\begin{abstract}
This article aims to present a contribution to the debate regarding curricular reform of the undergraduate course of Geology-USP, based on the recent employment of geologists in projects regarding investigation and remediation of contaminated sites. This area is experiencing considerable expansion, especially after the enforcement of the Federal Law 9605, regarding Environmental Crimes, in 1999. Even after all efforts in the conduction and completion of the existing cases of contamination, it is recognized that most of such environmental problems still remain unknown, which leads one to believe that there will be a tendency for growth in the demand for new professionals to work in this area at the long term. Considering that the geologist performs a vital and notable role in the characterization of geology, hydrogeology and contamination in an investigation and remediation project, it is believed that some courses should be adjusted to meet some of the professional activities mentioned in the CONFEA Resolution 1010, which regulates the professional activities of the geologist. Besides this, a re-evaluation of the duration, content and sequencing of some of the fundamental geological disciplines is believed to be necessary. This will result in benefits which affect not only the action of the geologist in projects on contaminated areas, but also in other areas of applied geology.
\end{abstract}




\section{APRESENTAÇÃO}

Este trabalho objetiva apresentar uma contribuição à discussão da reforma curricular do curso de Geologia-USP levando-se em consideração a demanda promovida pela sociedade para a atuação do profissional geólogo em projetos de investigação e remediação de áreas contaminadas.

As observações e avaliações contidas no artigo são realizadas sob a ótica da experiência profissional do autor na coordenação de equipes de profissionais em projetos de investigação e remediação de áreas contaminadas na iniciativa privada, e também sob a perspectiva do futuro exercício da Resolução CONFEA 1010, de 22/08/2005, que regulamenta e define os campos de atuação do geólogo e dos demais profissionais inseridos no Sistema CREA.

Entende-se, portanto, que a discussão da reforma curricular neste momento seja de interesse da comunidade pois, em paralelo à nova regulamentação profissional referida, ocorreram mudanças importantes na demanda de profissionais geólogos após a última reforma do currículo, ocorrida em 1994, notadamente com relação à atuação dos geólogos em problemas ambientais.

Embora este texto se refira à avaliação do currículo à luz da atuação do geólogo em projetos de investigação e remediação de áreas contaminadas, entende-se que o currículo deve atender, de forma equânime, às necessidades geradas pela sociedade relacionadas com todas as áreas aplicadas da Geologia, como a Mineração, Geologia do Petróleo, Geologia de Engenharia, Hidrogeologia e Geologia Ambiental. Espera-se, entretanto, que as argumentações expostas no texto tenham também aplicabilidade para as demais áreas da Geologia Aplicada.

Apresenta-se em seguida uma avaliação do tamanho do problema social gerado pela ocorrência de áreas contaminadas no âmbito do Estado de São Paulo, e uma descrição dos papéis e da importância do geólogo na condução de projetos nesta área. Em seguida, realiza-se uma breve comparação entre a grade curricular atual e as demandas promovidas pela Resolução CONFEA 1010, acompanhada de algumas reflexões sobre os pontos que necessitam atenção para efeito de alteração do currículo.

\section{A DEMANDA SOCIAL PARA A ATUAÇÃO DO GEÓLOGO EM ÁREAS CONTAMINADAS}

A questão da contaminação do solo e das águas subterrâneas tem sido objeto de grande preocupação nas três últimas décadas em países industrializados, especialmente nos Estados Unidos e na Europa. Esse problema ambiental torna-se mais grave em centros urbanos e industriais, como a Região Metropolitana de São Paulo.
A contaminação do solo pode ser fonte de poluição do ar, das águas superficiais e subterrâneas e pode causar riscos para a saúde pública e para o meio ambiente e, em condições mais críticas, pode originar riscos de incêndio e de explosão, além de provocar substanciais danos econômicos. Entretanto, na maioria das vezes, a existência de uma área contaminada é desconhecida pela população potencialmente afetada.

Os meios de comunicação de massa têm noticiado, recentemente, vários casos de contaminação de solo com conseqüências para a população imediata. Vários são os exemplos de casos que ganharam a mídia com destaque:

1. a construção de condomínios residenciais em antigas áreas industriais contaminadas (ex. Condomínio Barão de Mauá - Mauá, SP);

2. vazamento de tanques de combustíveis provenientes de postos de abastecimento, com posterior acúmulo de gases tóxicos e explosivos em galerias e garagens subterrâneas;

3. a contaminação da água subterrânea por atividades industriais, posteriormente captada por poços de uso doméstico (Aterro Industrial Mantovani - Sto. Antonio de Posse; Shell - Paulínia; Shell - Vila Carioca, SP; complexo industrial de Santo Amaro, SP).

Todos esses casos tiveram, como conseqüências, a exposição de seres humanos, fauna e flora a compostos que geram efeitos adversos à saúde. Além disso, a existência de uma área contaminada pode provocar danos econômicos substanciais, já que a remediação é uma atividade cara e que dificilmente promove uma limpeza efetiva do meio nos mesmos padrões existentes anteriores ao impacto, levando à inutilização do bem "água subterrânea" como fonte de água potável.

Considerando-se apenas os números de áreas potencialmente contaminadas relativos ao Estado de São Paulo, que representa cerca de metade do Produto Interno Bruto do Brasil, aponta-se para a existência de cerca de 8.400 postos de abastecimento de combustíveis, 2.400 destes somente na Região Metropolitana de São Paulo (CETESB, 2006). Estima-se, ainda, a existência de cerca de 160.000 indústrias, sendo que aproximadamente de 10 a $15 \%$ delas apresentam potencial poluidor, o que resulta em pelo menos 16.000 áreas com potencial existência de contaminação. Além disso, levantamento realizado indicou a existência de cerca de 4.300 áreas industriais antigas e abandonadas na RMSP, sendo que cerca de 2.000 delas apresentam potencial poluidor $(\mathrm{Cu}-$ nha, 1997). Outras importantes fontes de contaminação do solo e da água subterrânea em ambiente urbano são, ainda, os vários aterros sanitários, controlados e lixões existentes.

Deste total, porém, a CETESB, segundo dados de novembro de 2005, computa a existência de apenas 1.596 áreas con- 
taminadas, sendo que este número correspondia a apenas 255 casos três anos antes. Depreende-se destes dados que houve um grande esforço deste órgão em descobrir novos casos, mas que o número final é ainda pequeno (6\%) frente ao potencial poluidor existente no Estado de São Paulo.

Do total de áreas cadastradas, cerca de 73\% corresponde a vazamentos em postos de combustível e apenas 16\% a áreas industriais. O maior número de casos relacionados a postos de combustível relaciona-se com o condicionamento da liberação da Licença de Operação pela CETESB à obrigatoriedade destes estabelecimentos em apresentar relatórios de avaliação ambiental. Comparando-se o número total de indústrias com potencial poluidor no Estado de São Paulo (16.000) e com o número confirmado de áreas contaminadas em ambiente industrial (254), conclui-se que vários novos casos de contaminação em ambiente industrial ainda deverão ser detectados no futuro.

A situação atual mostra que há ainda muito por fazer. Do total das 1.596 áreas contaminadas, apenas $2 \%$ encontra-se em situação de remediação concluída, 35\% encontra-se com remediação em andamento, mas 54\% dos casos possui contaminação confirmada, mas ainda sem proposta de remediação definida e apresentada. Dos métodos de remediação escolhidos, a grande maioria dos casos corresponde à simples contenção hidráulica da pluma de contaminação (método de bombeamento e tratamento), seguida pela remoção de produto puro (fase livre) por bombeamento/escavação (CETESB, 2006). Trata-se de métodos que não destroem o contaminante no solo/aqüífero, mas apenas bloqueiam a sua migração no meio.

O mercado de serviços em áreas contaminadas encontra-se fortemente aquecido nos últimos 5 anos, período este que coincide com o avanço expressivo no número de casos conhecidos de contaminação. Este avanço tem origem no surgimento da Lei Federal 9605 de Crimes Ambientais (de 12/1/1998), que dispõe sobre as sansões penais e administrativas derivadas de condutas e atividades lesivas ao meio ambiente, e sua regulamentação através do Decreto 3179, de 21/09/1999. A aplicação desta legislação no âmbito de todo o país certamente demandará serviços e profissionais para atuar na área de investigação e remediação de áreas contaminadas de forma contínua em longo prazo.

Os números de casos conhecidos, somente no Estado de São Paulo, ainda não são maiores devido à escassez de profissionais especializados nesta área e que poderiam atuar de forma eficaz, tanto na iniciativa privada (como técnicos em empresas de consultoria e na indústria) como no Estado (como técnicos dos órgãos ambientais do Estado e municípios). Dado que a parcela de áreas contaminadas conhecidas é diminuta em relação às áreas potenciais e que esta parcela ainda demandará muito tempo para ser remediada de forma plena, prevê-se que este mercado ainda crescerá expressivamente nos próximos anos, demandando um grande número de novos profissionais, dentre os quais o geólogo tem papel de destaque.

\section{A NATUREZA DO TRABALHO DO GEÓLOGO EM ÁREAS CONTAMINADAS}

A abordagem do problema de áreas contaminadas tem caráter multidisciplinar, podendo envolver vários tipos de profissionais especializados, como geólogos, geógrafos, biólogos e engenheiros, desde a fase da descoberta do problema até a sua efetiva correção. Um projeto genérico nesta área estrutura-se nas etapas de:

a. auditoria ambiental;

b. investigações diretas;

c. modelações matemáticas;

d. avaliação de risco toxicológico;

e. definição da alternativa de remediação;

f. projeto e implementação do sistema de remediação;

g. operação, manutenção e monitoramento.

A etapa de auditoria ambiental identifica as matérias primas, produtos finais e resíduos gerados, bem como os processos que foram executados no tempo e no espaço em uma determinada área de interesse ambiental, visando identificar os locais específicos que poderiam estar potencialmente contaminados. Embora esta etapa não exija conhecimentos de Geologia tradicional para a sua complementação, o geólogo tem amplas condições de atuação nesta etapa decorrente de sua noção temporal e espacial desenvolvida no curso de Geologia, assim como de sua habilidade na utilização e interpretação de imagens aéreas.

Na etapa de investigação direta, confirma-se, no campo, a existência de passivos ambientais em locais específicos apontados na fase de auditoria ambiental. É nesta fase que o trabalho do geólogo é mais rico na aplicação de diversos conceitos obtidos a partir das disciplinas fundamentais e aplicadas do curso de Geologia. Esta etapa é executada tantas vezes quantas forem necessárias até que se complete a delimitação espacial da contaminação do solo e da água subterrânea. As tarefas relacionadas com esta etapa são a definição da estratégia de investigação, a execução de mapeamento geológico de superfície, locação e execução de sondagens, quantificação e delimitação espacial de resíduos enterrados e solos impactados por métodos diretos e indiretos (geofísica), instalação de poços de monitoramento, execução de testes hidráulicos, perfilagem geofísica, e a definição e execução de plano de amostragem e de análises químicas de resíduos, solos e águas. Nesta etapa, vários perfis geológicos e hidrogeológicos, além de mapas de fluxo de água subterrânea e mapas de isoconcentração de contaminantes são 
construídos, visando definir os modelos conceituais da geologia, hidrogeologia e da contaminação na área de estudo, que são a base para a execução dos trabalhos posteriores de engenharia de remediação que porventura sejam necessários de se executar. $\mathrm{O}$ sucesso ou o fracasso do saneamento de uma área contaminada advém da qualidade do trabalho executado pelo geólogo nesta fase do projeto.

Na etapa de modelação matemática, os modelos conceituais de geologia, hidrogeologia e de contaminação são utilizados para se quantificar a dinâmica de fluxo e transporte dos contaminantes, visando estabelecer cenários futuros do comportamento da contaminação, definir concentrações futuras em pontos de exposição e testar hipóteses de remediação. $\mathrm{O}$ passo seguinte é definir se a contaminação observada e modelada gera riscos ambientais. Existem metodologias específicas de avaliação de risco ambiental que objetivam, em última análise, quantificar os riscos e determinar as metas de remediação a serem atingidas pelo sistema de remediação escolhido, caso tais medidas sejam apontadas como necessárias pela avaliação de risco. O profissional geólogo tem plenas condições de executar as tarefas de modelação matemática e de avaliação de riscos, tanto que a Resolução CONFEA 1010 prevê estas atividades como de seu campo de atuação.

No caso de haver riscos ambientais e à saúde humana, medidas diretas de saneamento ambiental deverão ser realizadas. A escolha da técnica de remediação é função de uma série de variáveis, como a viabilidade técnica e implementabilidade, a melhor relação custo-benefício, além das propriedades dos contaminantes, do meio físico, do estado da arte das tecnologias de remediação e das exigências da agência ambiental. As tecnologias de remediação disponíveis enquadram-se nos seguintes grupos:

1. escavação e disposição de solo/resíduo;

2. contenção física de solo/resíduo contaminado (capeamento) ou de água subterrânea contaminada (sistema de bombeamento e tratamento);

3. volatilização de contaminantes (sistemas de injeção ou sucção de ar no solo/aqüífero);

4. tratamento biológico;

5. oxidação química in situ.

A definição da alternativa de remediação é uma importante etapa onde há uma interface de atuação do geólogo e do engenheiro, em que o primeiro possui uma visão mais perspicaz do comportamento da contaminação no espaço e no tempo, enquanto que o segundo possui uma visão mais aguçada da exeqüibilidade das ações de saneamento.

Após o estudo de alternativas apontar qual sistema de remediação é mais adequado para o caso, passa-se para a elaboração dos projetos básico e executivo do sistema, seguida de sua implementação, operação, manutenção e monitoramento. Embora a maior parte dessas tarefas seja mais afeita ao engenheiro, cabe ao geólogo acompanhar as tarefas de acompanhamento dos resultados da remediação, monitorando a redução das concentrações de contaminantes no solo e na água subterrânea até que os objetivos da remediação, definidos na etapa de avaliação de riscos, sejam atingidos. Quando necessário, cabe também ao geólogo apontar os ajustes necessários ao sistema para que as metas de remediação sejam alcançadas de forma mais eficaz.

Observa-se, portanto, que cada projeto em áreas contaminadas compõe-se de um conjunto de tarefas que o torna complexo, único e de natureza investigativa, cujo sucesso depende de uma seqüência de decisões da qual o geólogo assume papel de destaque. Notadamente nas fases de investigação e modelação matemática, somente o geólogo possui os pré-requisitos necessários para a realização das tarefas de forma apropriada. Nas fases de auditoria ambiental, avaliação de risco e monitoramento do sistema de remediação, o geólogo tem plenas condições de atuação, juntamente com profissionais de outras áreas. Somente as fases de execução do projeto do sistema de remediação e a sua implementação, operação e manutenção apresentam atividades mais relacionadas com a atuação de engenheiros, apesar de não haver impedimentos para que os geólogos também se desenvolvam nestas áreas.

Dentre as disciplinas fundamentais que caracterizam a formação do geólogo durante a graduação, algumas são da mais absoluta importância para que o profissional atue de forma plena em projetos de áreas contaminadas. Elas são a Sedimentologia, a Estratigrafia, a Geoquímica de Superfície e a Geologia Estrutural. O conteúdo das duas primeiras tem utilização intensa durante o processo de caracterização do meio geológico, tanto através da descrição e interpretação de afloramentos em superfície como através da descrição de testemunhos de sondagem, dada a necessidade de se realizar um modelo conceitual da geologia baseada na identificação de fácies sedimentares e nas suas relações estratigráficas. A caracterização minuciosa do meio físico geológico é fundamental para o entendimento de como a água e o contaminante se encontram e se deslocam no aqüífero.

A geoquímica de superfície é um assunto importante para a formação do geólogo que atua em áreas contaminadas pois os contaminantes em geral atravessam os horizontes pedológicos existentes antes de atingir os níveis aqüíferos. Uma ampla gama de interações químicas ocorre entre o contaminante e o material intemperizado, destacando-se o papel de retenção dos contaminantes orgânicos e inorgânicos, respectivamente, pela matéria orgânica sólida e por argilominerais e óxidos-hidróxidos de ferro. $\mathrm{O}$ intemperismo é um processo importante na geração de 
porosidade por fraturas atectônicas subhorizontais em contexto geológico de rochas cristalinas, na interface da rocha alterada com a rocha sã. Tais fraturas geram áreas de elevada condutividade hidráulica, tornando os contaminantes muito mais móveis no aqüífero.

A Geologia Estrutural tem elevada importância, notadamente com relação ao tópico da tectônica rúptil. Os projetos de investigação e remediação de aqüíferos em contexto de rochas cristalinas fraturadas apresentam elevados custos, requerem aplicação de tecnologia de ponta e estão dentre os mais complexos de se executar, dado o caráter altamente anisotrópico do aqüífero e às mais elevadas velocidades de deslocamento do contaminante. O desenvolvimento de estudos de tectônica rúptil é necessário para a identificação das diferentes famílias de fraturas representativas dos diferentes eventos tectônicos. Em geral, procurase identificar os conjuntos de fraturas de tração dos eventos tectônicos tardios, que são os principais responsáveis pelo deslocamento da água subterrânea contaminada no aqüífero cristalino.

\section{A RESOLUÇÃO CONFEA 1010 E AS DISCIPLINA̧S EXISTENTES}

Em paralelo com as disciplinas fundamentais mencionadas acima, o atual currículo do curso de Geologia do IGc-USP apresenta as seguintes disciplinas aplicadas (obrigatórias e eletivas) que complementam a formação do geólogo que atua na área de investigação e remediação: Hidrogeologia e Recursos Hídricos, Geofísica Aplicada, Prospecção Pesquisa e Avaliação de Jazidas, Poluição de Recursos Hídricos, Hidrogeoquímica, Urbanização Industrialização e Meio Ambiente, Obras de Captação e Monitoramento de Águas Subterrâneas, Geofísica Aplicada ao Estudo de Poluição Subterrânea e Geoquímica Ambiental.

O Anexo II da Resolução CONFEA 1010 enumera vários campos de atuação profissional e de atividades do geólogo, boa parte deles apresentando relação direta com as atividades de investigação e remediação de áreas contaminadas. Entretanto, as ementas das disciplinas aplicadas acima mencionadas não cobrem as seguintes atividades definidas pela Resolução CONFEA 1010 como atribuição do geólogo: Implantação de Aterros de Resíduos Sólidos, Controle da Poluição Ambiental do Meio Físico, Modelagem Matemática, Remediação de Aqüíferos e Análise de Riscos.

Esta situação implica que o CREA poderá impor restrições ao geólogo na execução destas atividades, que representam grande parte dos projetos de investigação e remediação de áreas contaminadas que o geólogo já tradicionalmente executa. Esta possibilidade mais que justifica a necessidade de se realizar mudanças no conteúdo curricular do curso de Geologia.

\section{CONCLUSÕES}

As argumentações apresentadas levam à conclusão de que a sociedade tem demandado grande atenção para a resolução dos problemas ambientais gerados pelas áreas contaminadas existentes, com tendência de elevação desta demanda, dado que a maior parte dos problemas ainda não é conhecida. Além disso, cada projeto de investigação e remediação é de longa duração, podendo levar vários anos desde a fase da descoberta do problema até a sua complementação, com a efetiva remediação. Mencionouse, também, que um projeto de investigação e remediação de áreas contaminadas confere ao geólogo um papel de destaque na sua execução, principalmente nas etapas de caracterização da geologia, hidrogeologia e da contaminação, que são a base para a atuação da engenharia de remediação, propriamente dita.

A Resolução CONFEA 1010 possibilita ao geólogo a execução de várias atividades ligadas à investigação e remediação de áreas contaminadas, porém o atual currículo do curso de Geologia do IGc-USP apresenta-se incompleto na possibilidade de atuação do geólogo nas atividades de Implantação de Aterros de Resíduos Sólidos, Controle da Poluição Ambiental do Meio Físico, Modelagem Matemática, Remediação de Aqüíferos e Análise de Riscos. Tais deficiências poderiam ser supridas com a mudança das ementas das disciplinas profissionalizantes existentes, ou mesmo com a criação de disciplinas eletivas específicas.

Além disso, com relação às disciplinas fundamentais que caracterizam a formação do geólogo, nota-se uma necessidade de haver uma atenção maior ao assunto de geoquímica de superfície, que não possui disciplina específica no curso de graduação. Além das justificativas apresentadas acima com relação à aplicação do assunto no âmbito de áreas contaminadas, a geoquímica de superfície tem conteúdo importante como base para a atuação de profissionais em áreas aplicadas, como a Geologia de Engenharia, Geotecnia (da qual a subárea de riscos geológicos tem importância social de destaque) e Geologia Econômica (especialmente com relação aos depósitos minerais lateríticos).

Conclui-se, portanto, pela necessidade de se proceder a uma alteração no currículo do curso de Geologia, de forma a ser possível atender, de forma equilibrada, às necessidades que a sociedade demanda atualmente. Considerando que existem vários campos de atuação do geólogo, parece improvável a possibilidade de que todas as áreas de atuação sejam aprofundadas no curso de graduação, principalmente à luz da necessidade de se proceder a uma redução da carga horária do curso, já atualmente bastante intensa (4.575 horas).

A reforma do currículo deveria se dar, portanto, na reavaliação do tempo e conteúdo das disciplinas geológicas fundamentais que apóiam a atuação plena do geólogo, 
especialmente em áreas aplicadas. Assuntos mais específicos, tanto das disciplinas fundamentais como das disciplinas aplicadas, deveriam ser tratadas em cursos do nível de pós-graduação e, possivelmente, em cursos de extensão. Além disso, uma reavaliação da organização temporal das disciplinas deveria ser realizada, objetivando obter uma ordenação mais lógica da seqüência de algumas disciplinas, que facilitaria o processo de formação do aluno, e também de forma a se evitar a concentração de carga didática em determinadas épocas do curso.

Finalmente, como ponto para reflexão e considerando a necessidade de se reduzir a carga horária do curso, indicase como favorável a realização, por parte dos professores, de um exame do projeto pedagógico de suas disciplinas, de forma que haja uma adequação dos seus conteúdos aos respectivos tempos destinados para a condução das disciplinas. Tal avaliação deveria ser realizada levando-se em conta tanto o tempo despendido pelos alunos dentro da sala de aula como também no tempo exigido para estudos e trabalhos complementares, de forma a se evitar que a atenção dos alunos seja exigida por duas ou mais disciplinas simultaneamente.

\section{REFERÊNCIAS BIBLIOGRÁFICAS}

CETESB. Disponível em: <http://www.cetesb.sp.gov.br>. Acesso em: 08 mai. 2006.

CUNHA, R. C. A. Avaliação de risco em áreas contaminadas por fontes industriais desativadas: estudo de caso. 1997. 152 f. Tese (Doutorado) - Instituto de Geociências, Universidade de São Paulo, São Paulo, 1997. 